\title{
ON THE PROBLEM OF PROVIDING ELECTROMAGNETIC COMPATIBILITY OF POWER SOURCES OF RESISTANCE WELDING MACHINES WITH ELECTRIC MAINS
}

\author{
S.K. PODNEBENNAYA, V.V. BURLAKA and S.V. GULAKOV \\ State Higher Educational Establishment «Pre-Azov State Technical University» (PSTU) \\ 7 Universitetskaya Str., 87500, Mariupol, Ukraine. E-mail: office@pstu.edu
}

\begin{abstract}
In the work the problems of providing electromagnetic compatibility of power sources of single-phase resistance welding machines with three-phase supply mains were studied. The two basic directions were considered: the application of active filter-compensating and balancing devices (AFCBD) and the development of power sources (PS) with the power factor correction (PFC). The application of AFCBD allows using the existing welding equipment, but the high cost limits its wide application. PS with PFC assumes the use of converters either with DC link, or with direct matrix converters, as far as the basic requirement to PS for welding machines is the possibility of generating output voltage of preset shape, amplitude and frequency. In the article the method of control of three phase-single phase matrix converter with six switches was considered, which allows generating the output voltage of rectangular shape of $50 \mathrm{~Hz}$ frequency. The selection of frequency was predetermined by application of welding transformer, designed for operation at mains frequency. The shape of voltage was selected from the conditions of providing the minimum losses of power in the mains and inadmissibility of saturation of the welding transformer. The authors suggested also the circuit solution and the method of control of matrix converter with five switches, which during generation of output voltage, synchronized with the mains, allows obtaining the power factor of PS close to one. The analysis of sensitivity of the proposed power source to deviation of voltages was carried out, as a result of which it was determined, that at generation of rectangular voltage it was possible to achieve the stable operation at the voltage deviations of about $10 \%$, due to which the quality of welded joints was significantly increased. 11 Ref., 3 Tables, 5 Figures.
\end{abstract}

Keywords : resistance welding machine, power source, matrix converter, power factor, electromagnetic compatibility

The power sources (PS) of resistance welding machines are powerful non-linear consumers of electric mains. In most of them the thyristor control circuits are applied. Furthermore, such PS, being mostly single-phase, at their connection to three-phase mains (especially at switching and simultaneous operation of several PS of machines at different phases), have a negative influence on it. This is expressed in growth of asymmetry coefficients and non-sinusoidal voltage [1-4]. The deterioration of quality of supply voltage affects in its turn the quality of welding, moreover, the most significant is the deviation of voltage, which at excess of $15 \%$ results in $100 \%$ rejection (for corrosion-resistant steels $100 \%$ rejection is caused by the deviation of voltage to the amount of more than $10 \%$ ) [5]. Thus, the solution of problem of providing electromagnetic compatibility of welding equipment with electrical mains is an urgent problem.

The solution of the specified problem is possible in two directions: the application of additional active filter-compensating and balancing devices (AFCBD) [6], or the development and application of PS with a

(c) S.K. PODNEBENNAYA, V.V. BURLAKA and S.V. GULAKOV, 2016 power factor correction (PFC) $[4,7,8]$. The realization of the first variant allows providing the required (not always single) power factor (PF) of the complex «welding power source - AFCBD», reduces the losses of power in electrical mains, provides symmetrical loading of three phases in operation of single-phase power source in the three-phase mains. The advantage of such approach is retaining of the existing welding PS during the technological process without any modifications. The basic drawback of the first variant is its low profitability, as far as the cost of AFCBD is commensurable with the cost of PS itself.

The other direction for solution of the formulated problem is the PS updating. It has prospects in connection with development of power electronics and appearance of powerful and quick-response power switches, allowing switching the high loads.

In the works $[9,10]$ the circuit solutions were considered aimed at updating PS by applying thyristor converters of three-phase voltage to a single phase, allowing providing a symmetric (or quasi-symmetric) consumption of currents. The main disadvantage of these circuits is a high ratio of non-sinusoidal currents 
consumption (up to 80-90\%) and the need in applying a low-frequency transformer, caused by the decreased frequency of output voltage, generated by the thyristor converter.

For today the more effective is the development of transistor PS, which are designed mainly on the basis of power converters with an intermediate link of direct current (rectifier, DC link, inverter). The connection of such converters to electric mains is carried out through input three-phase LC-filter, isolating the mains from the modulation current components, generated by the converter.

At the symmetric system of mains voltages, the application of uncontrolled rectifier (for example, sixpulse one) provides the consumption of symmetric currents from mains [8]. However, at asymmetrical mains voltages, the symmetry of the consumed currents is also violated. In addition, the spectral composition of currents consumed by the six-pulse rectifier, does not allow providing its electromagnetic compatibility with mains without installation of AFCBD in accordance with the standards established by GOST 13109-97, DSTU IES 61000-3-2:2004, 61000-3-4:2004.

The topologies of inverters, which are the most frequently used for such PS, are bridge, half-bridge and push-pull, as far as they allow providing the absence of a permanent component of magnetic flux in the transformer. The push-pull and bridge inverters generate a bipolar voltage at the output of converter, the maximum value of which is equal to the voltage of DC link. The disadvantage of push-pull inverter is the need in using switches, capable to withstand a double voltage of DC link; among the disadvantages of bridge inverter is an increased number of power switches (four at the bridge against two in the pushpull ones). The half-bridge inverter, consisting of two switches, generates an output voltage, the maximum value of which is equal to half of the voltage of DC link, which is its drawback [8].

The installation of PF corrector on the input of the converter allows providing the sinusoidal currents consumption [7], however it slightly reduces the technical and economic characteristics of the power source in connection with an increased number of controlled power switches.

PS with PFC on the base of converters with an intermediate DC link are quite effective, but their wide application is hindered by the high cost. In addition, there is a problem in reliability of energy storage device in the DC link as well as the need in introducing the special circuits for limiting charge current of capacitors at connection of the power source to mains.

Therefore, for today the investigations are directed mainly to reducing the cost of such PS. It provides

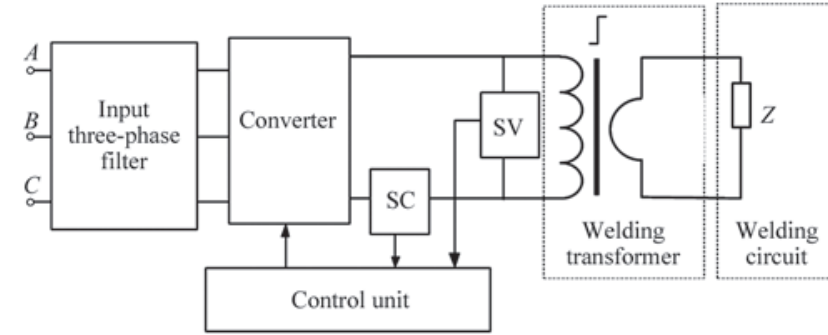

Figure 1. Schematic block diagram of MRW connection to mains possibility to formulate the aim of the article, which consists in development of effective power source for resistance welding machine, providing a high quality of welding process and electromagnetic compatibility with mains.

The authors proposed to study PS of MRW, which consists of a welding transformer, a converter, installed into the primary circuit of transformer and an input filter, switched on between converter and mains (Figure 1). As input signals for control of converter, the initial current and voltage serve, measured by the respective sensors (SC, SV), and the mains voltage. As the converter of PS of MRW, it is proposed to use a direct matrix converter (MC), a feature of which is that an intermediate link of direct current (usually capacitor of high capacity) is absent, which significantly increases the technical and economic indicators of the converter.

Three-phase-single-phase MC consists of six bidirectional switches, each of which switches on one of the phases of mains directly to the load (Figure 2). The bidirectional switches can be designed in the form of two transistors with reverse diodes, having an inverse-series connection, and the controlling electrodes of transistors are connected to a control unit (CU).

It is known that the minimum of power losses in the electric mains at the connection of load to it can be obtained by providing the proportionality between the consumed currents and the corresponding phase voltages [11]. Thus, MC should simulate the symmetrical active load.

The instantaneous active power of three-phase mains is determined as the sum of instantaneous active powers of all three phases:

$$
\begin{gathered}
p(t)=p_{A}(t)+p_{B}(t)+p_{C}(t)= \\
=\left(u_{A}(t)\right)^{2} / R+\left(u_{B}(t)\right)^{2} / R+\left(u_{C}(t)\right)^{2} / R,
\end{gathered}
$$

where $p_{A}(t)=\left(u_{A}(t)\right)^{2} / R$ is the instantaneous phase power $A ; p_{B}(t)=\left(u_{B}(t)\right)^{2} / R$ is the instantaneous phase power $B ; p_{C}(t)=\left(u_{C}(t)\right)^{2} / R$ is the instantaneous phase power $C$, $R$ is the simulated active load, Ohm; $u_{A}(t), u_{B}(t), u_{C}(t)$ are the instantaneous phase voltages of mains, $\mathrm{V}$.

For symmetrical voltages and load the instantaneous power, consumed by the latter, is a constant value. At the same time, due to absence of energy ca- 


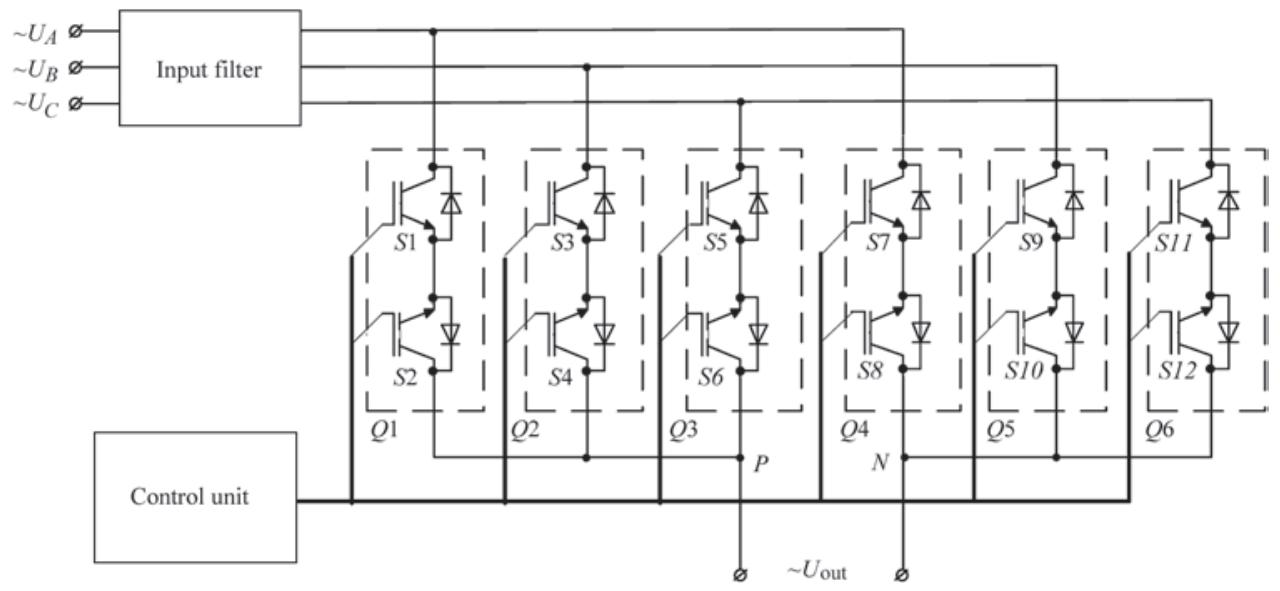

Figure 2. Simplified electric circuit of matrix converter

pacitor, MC itself is not a consumer of active power (excluding the losses of power in the power switches, which in the meantime can be neglected). It follows from this, that to provide a symmetric consumption of currents, MC should operate at a constant active power.

$$
P=U(t) I(t)=\text { const, }
$$

where $U(t)$ is the output voltage of $\mathrm{MC}, \mathrm{V} ; I(t)$ is the output current of MC, A.

If we neglect the influence of inductance of welding circuit on the output current of the converter, it can be assumed with an admissible error that the symmetrical consumption of MC currents is possible at the generation of constant voltage at its output. Moreover, the constant component of the current, passing through the primary winding of welding transformer, will lead to increase in magnetization and significant power losses.

This can be avoided by providing a change in polarity of MC output voltage in accordance with the expression:

$$
\int_{0}^{T_{\text {out }}} U(t) d t=0,
$$

where $T_{\text {out }}$ is the period of MC output voltage, s.

At asymmetric system of mains voltages the instantaneous active power of three-phase mains, determined by the expression (1) is not a constant value, then the control of converter can be realized from the condition of the preset active power consumption averaged over the period of mains, which is controlled by changing the simulating active resistance $R$. Here, the simulating active resistance should not vary during the period of mains not to generate the low-frequency harmonics.

Let us consider the symmetrical voltage system, and, according to the abovementioned assumption, let us carry out the generation of rectangular voltage with $50 \mathrm{~Hz}$ frequency at the output of MC. Let us accept the initial phase shift of the voltage phase $A$ as equal to zero. Let us conditionally divide the period of mains into six sectors: to the first and the fourth sector the highest absolute value of the instantaneous voltage of the phase $B$ corresponds (the first is at the negative voltage of the phase $B$, the fourth is at the positive one), to the second and the fifth - of the phase $A$ (the second at the positive voltage of phase $A$, the fifth at the negative one), the third and the sixth - to phase $C$ (the third is at the negative voltage of phase $C$, the sixth is at the positive one).

The duty cycles of the controlling pulses of switches $Q 1-Q 6$ are calculated according to the following expressions:

$$
\begin{gathered}
D_{1}=\frac{u_{A}(t)}{R I(t)} ; \quad D_{2}=-\frac{u_{B}(t)}{R I(t)} ; \quad D_{3}=-\frac{u_{C}(t)}{R I(t)} ; \\
D_{4}=-D_{1} ; \quad D_{5}=-D_{2} ; \quad D_{6}=-D_{3} .
\end{gathered}
$$

The selection of the necessary pair of switches for the positive polarity of the output voltage occurs in the control unit in accordance with the Table 1.

A single duty cycle of pulse in the Table means that in the given sector the switch is switched on constantly. To generate the output voltage of negative polarity, the signals of control of switches Q1-Q3 and Q4-Q6 change their places with each other (Table 2).

The formation of output voltage with $50 \mathrm{~Hz}$ frequency allows achieving one more effect: at synchronization of output voltage with one of the mains voltage (for example, phase A), a number of power switches of converter can be reduced to five (Figure 3). The duty cycles of the controlling pulses of switches of the converter with five switches are calculated in accordance with (4) and are presented in Table 3.

The application of MC with five switches allows preserving all the properties and advantages of classic MC with six switches, excluding the possibility of changing the output frequency, but in view of the overwhelmed majority of welding PS designed for 
Table 1. Distribution of control signals of switches depending on number of sector for positive polarity of output voltage

\begin{tabular}{|c|c|c|c|c|c|c|}
\hline \multirow{2}{*}{ Number of switch } & \multicolumn{6}{|c|}{ Sector of mains period } \\
\hline & 1 & 1 & 3 & 4 & 5 & 8 \\
\hline Q1 & $D_{3}$ & 1 & $D_{1}$ & 0 & $1-D_{2}-D_{3}$ & 0 \\
\hline Q2 & $1-D_{3}-D_{3}$ & 0 & $D_{2}$ & 1 & $D_{2}$ & 0 \\
\hline Q3 & $D_{3}$ & 0 & $1-D_{1}-D_{2}$ & 0 & $D_{3}$ & 1 \\
\hline Q4 & 0 & $1-D_{5}-D_{6}$ & 0 & $D_{4}$ & 1 & $D_{4}$ \\
\hline Q5 & 1 & $D_{5}$ & 0 & $1-D_{4}-D_{6}$ & 0 & $D_{5}$ \\
\hline Q6 & 0 & $D_{6}$ & 1 & $D_{6}$ & 0 & $1-D_{4}-D_{5}$ \\
\hline
\end{tabular}

Table 2. Distribution of signals for control of switches depending on number of sector for negative polarity of output voltage

\begin{tabular}{|c|c|c|c|c|c|c|}
\hline \multirow{2}{*}{ Number of switch } & \multicolumn{6}{|c|}{ Sector of mains period } \\
\hline & 1 & 2 & 3 & 4 & 5 & 6 \\
\hline Q1 & 0 & $1-D_{5}-D_{6}$ & 0 & D4 & 1 & $D 4$ \\
\hline Q2 & 1 & $D_{5}$ & 0 & $1-D_{4}-D_{6}$ & 0 & $D_{5}$ \\
\hline Q3 & 0 & $D_{6}$ & 1 & $D_{6}$ & 0 & $1-D_{4}-D_{5}$ \\
\hline Q4 & $D_{1}$ & 1 & $D_{1}$ & 0 & $1-D_{2}-D_{3}$ & 0 \\
\hline Q5 & $1-D_{4}-D_{3}$ & 0 & $D_{2}$ & 1 & $D_{2}$ & 0 \\
\hline Q6 & $D_{3}$ & 0 & $1-D_{1}-D_{2}$ & 0 & $D_{3}$ & 1 \\
\hline
\end{tabular}

operation with the transformer of a commercial frequency, it is not a disadvantage.

As a result of mathematical modeling in the package MathCAD the diagrams of input currents, output voltage and current of MC with five switches were obtained (Figures 4, 5). The parameters of MC are as follows: switching frequency is $3.2 \mathrm{kHz}$, preset output voltage is rectangular, with $50 \mathrm{~Hz}$ frequency and the amplitude value of $300 \mathrm{~V}$; the leakage inductance, reduced to the primary winding, amounts to $0.6 \mathrm{mH}$, active resistance is $2.5 \mathrm{Ohm}$; inductance of input filter is $0.1 \mathrm{mH}$, capacitance of input filter is $24 \mu \mathrm{F}$. The coefficient of non-sinusoidal input current of the phase, synchronized with the output voltage of the converter, being at the switching frequency after filtering the components, is about $6 \%$. The power factor is about $95.6 \%$, the coefficient of asymmetry of input currents by reverse sequence is about $4 \%$.

Table 3. Distribution of signals for control of switches depending on number of sector for generating output voltage of matrix converter with five switches

\begin{tabular}{|c|c|c|c|c|c|c|}
\hline \multirow{2}{*}{$\begin{array}{c}\text { Number } \\
\text { of switch }\end{array}$} & \multicolumn{7}{|c|}{ Sector of mains period } \\
\cline { 2 - 7 } & 1 & 2 & 3 & 4 & 5 & 6 \\
\hline$Q 1$ & 1 & $D_{2}$ & 0 & 1 & $D_{2}$ & 0 \\
\hline$Q 2$ & 0 & $D_{3}$ & 1 & 0 & $D_{3}$ & 1 \\
\hline$Q 3$ & $D_{4}$ & 1 & $D_{4}$ & $D_{4}$ & 1 & $D_{4}$ \\
\hline$Q 4$ & $D_{5}$ & 0 & $D_{5}$ & $D_{5}$ & 0 & $D_{5}$ \\
\hline$Q 5$ & $D_{6}$ & 0 & $D_{6}$ & $D_{6}$ & 0 & $D_{6}$ \\
\hline
\end{tabular}

The power factor of the described PS of resistance welding machines is much higher than that in the existing thyristor ones, which usually does not exceed $60 \%$ [5]. Moreover, the switching of single-phase resistance welding machine to three-phase mains using the described PS, does not result in arising asymmetry and provides a symmetrical consumption of currents, close to sinusoidal as to the shape.

The application of MC for MRW power supply provides one more positive effect. When switching the welding transformer from the mains directly through the thyristor contactor [10], the maximum voltage, supplied to the primary winding, reaches $\sqrt{ } 3 U_{\mathrm{f}}$. The output voltage of MC is not higher than $1.5 U_{\mathrm{f}}$. However, at the rectangular shape of output voltage of MC with the maximum amplitude of $1.5 U_{f}$, the actual value of the first harmonics of voltage will

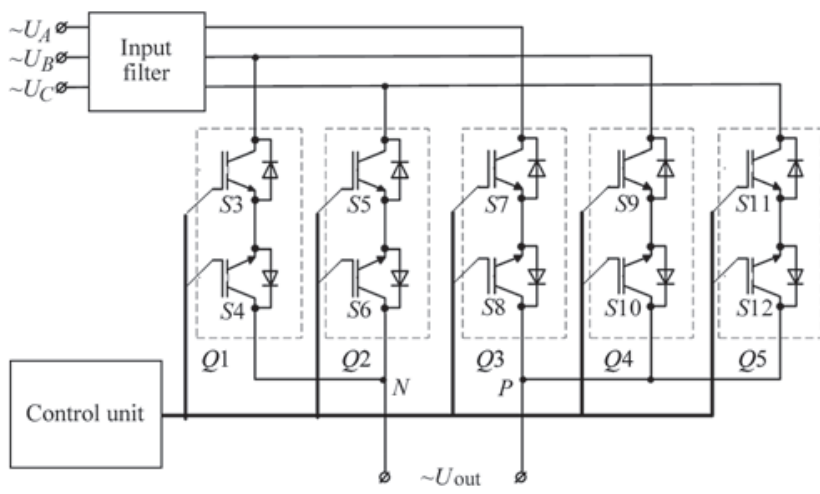

Figure 3. Simplified electric circuit of matrix converter with five switches 


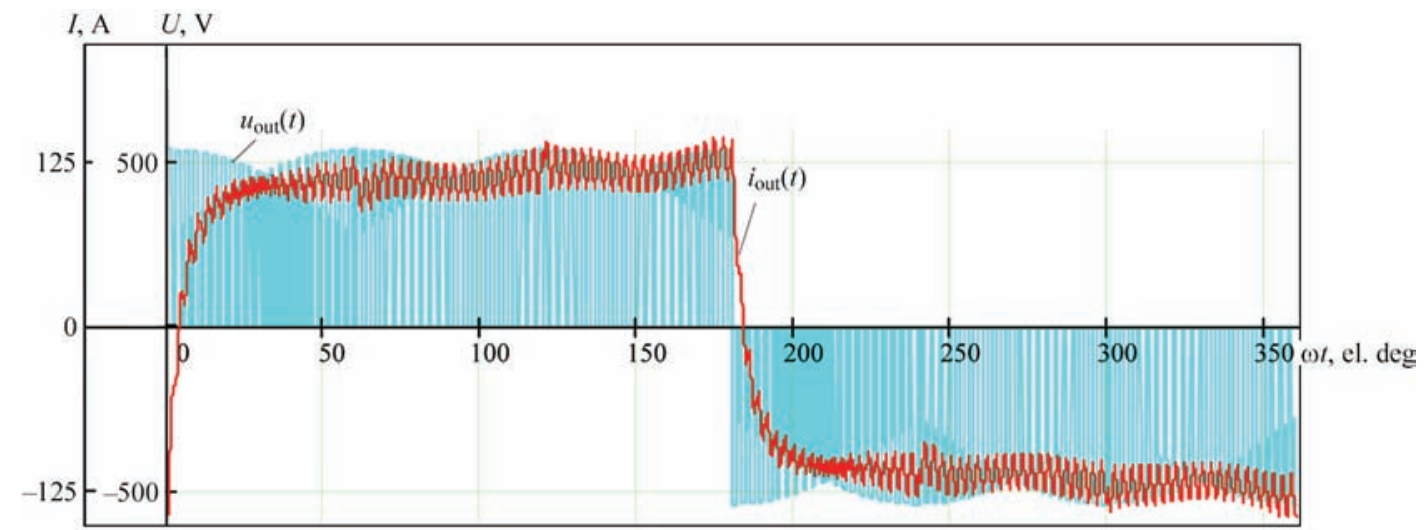

Figure 4. Diagrams of output voltages and current of $\mathrm{MC}$ with five switches

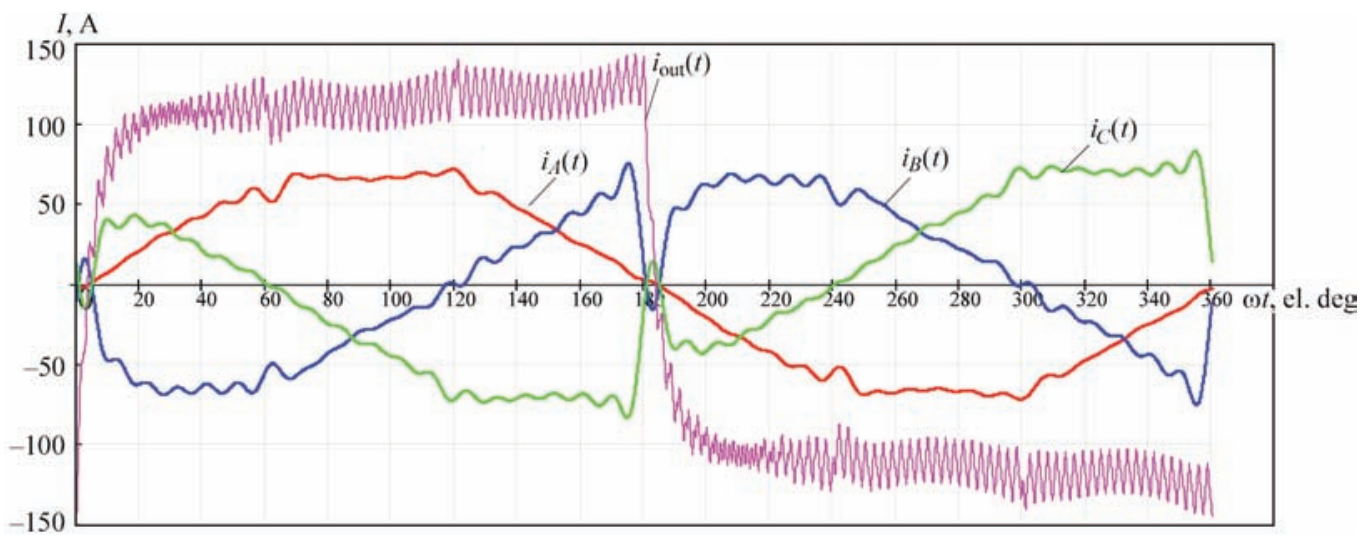

Figure 5. Diagrams of input currents of MC with five switches and its output current

amount to $6 U_{\mathrm{f}} / \pi$, that allows reducing the sensitivity to deviations of mains voltage, providing the margin of voltage of about $10 \%$ and increasing the quality of welded joints.

The application of the described converters and the method of their control allowed achieving the high quality of the resistance welding process, thus having provided a high power factor of PS and its electromagnetic compatibility with the mains.

1. Pismenny, A.A. (2014) Improvement of power efficiency of machines for resistance spot welding by longitudinal compensation of reactive power. The Paton Welding J., 1, 25-29.

2. Rudenko, P.M., Gavrish, V.S. (2013) Thyristor direct converters for supply of resistance welding machines. Ibid., 8, 54-56.

3. Rymar, S.V., Zhernosekov, A.M., Sidorets, V.N. (2011) Effect of single-phase power sources of welding arc on electric mains. Ibid., 12, 7-12.

4. Safronov, P.S., Bondarenko, Yu.V., Bondarenko, O.F. (2014) Improvement of electromagnetic compatibility of power sources for resistance welding systems. Tekhnichna Elektrodynamika, 5, 89-91.
5. Vagin, G.Ya. (1985) Modes of electric welding machines. Moscow: Energoatomizdat.

6. Podnebennaya, S.K., Burlaka, V.V., Gulakov, S.V. (2012) Decrease of disturbances generated by welding power sources using parallel active filter of higher efficiency. Visnyk DDMA, 28(3), 221-226.

7. Wagner, M., Kolb, S. (2013) Efficiency improvements for high frequency resistance spot welding. In: Proc. of $15^{\text {th }} \mathrm{Eu}-$ ropean Conf. on Power Electronics and Applications (EPE), $1-9$.

8. Saleem, J. (2012) Power electronics for resistance spot welding equipment. Mid Sweden University Licentiate Thesis. Sundsvall.

9. Lebedev, V.K., Pismenny, A.A. (2003) Power system of flashbutt welding machines with a transistor inverter. The Paton Welding J., 2, 10-12.

10. Lebedev, V.K., Pismenny, A.A. (2001) Power systems of resistance welding machines. Ibid., 11, 28-32.

11. Podnebennaya, S.K., Burlaka, V.V., Gulakov, S.V. (2013) Peculiarities of regulation of power parallel active filter. In: Proc. of $11^{\text {th }}$ Int. Sci.-Techn. Conf. of Junior Scientists and Specialists on Electromechanical and Power Systems, Methods of Modeling and Optimization (Kremenchuk, Ukraine, 9-11 April 2013), 168-169. 